\title{
Lactobacillus casei strain GG in the treatment of infants with acute watery diarrhea: A randomized, double-blind, placebo controlled clinical trial [ISRCTN67363048]
}

\author{
Eduardo Salazar-Lindo*1, Percy Miranda-Langschwager ${ }^{1}$, Miguel Campos- \\ Sanchez ${ }^{2}$, Elsa Chea-Woo ${ }^{1}$ and R Bradley Sack ${ }^{3}$
}

Address: ${ }^{1}$ Department of Pediatrics, Cayetano Heredia Hospital, Lima, Peru, ${ }^{2}$ Department of Physics and Mathematics, Cayetano Heredia University, Lima, Peru and 3Johns Hopkins Bloomberg School of Public Health, Department of International Health, Baltimore, Maryland, USA

Email: Eduardo Salazar-Lindo* - edsalaza@ec-red.com; Percy Miranda-Langschwager - percy_miranda@bonus.com.pe; Miguel CamposSanchez - viper@upch.edu.pe; Elsa Chea-Woo - echea@upch.edu.pe; R Bradley Sack - rsack@jhsph.edu

* Corresponding author

Published: 02 September 2004

BMC Pediatrics 2004, 4:18 doi:10.1/86/147|-2431-4-18

This article is available from: http://www.biomedcentral.com/|47/-243//4//8

(C) 2004 Salazar-Lindo et al; licensee BioMed Central Ltd.

This is an open-access article distributed under the terms of the Creative Commons Attribution License (http://creativecommons.org/licenses/by/2.0), which permits unrestricted use, distribution, and reproduction in any medium, provided the original work is properly cited.

\begin{abstract}
Background: Adjuvant therapy to ORT with probiotic bacteria for infants with acute watery diarrhea has been under active investigation. Most studies have been done in the developed world showing benefit only for viral mild gastroenteritis. We evaluated the effect of a milk formula containing one billion $\left(10^{9}\right) \mathrm{cfu} / \mathrm{ml}$ of Lactobacillus casei strain GG (LGG) upon duration and severity of diarrhea in infants in an environment with more severe acute diarrhea, where etiologic agents other than rotavirus are involved more frequently, and where mixed infections are more prevalent.
\end{abstract}

Methods: Male infants aged 3-36 months brought for treatment of acute watery diarrhea of less than 48 hours were eligible. After rehydration was completed with the WHO's oral rehydration solution, patients were randomly assigned to receive a milk formula either containing LGG or not. Stool volume was periodically measured using a devise suited to collect stools separate from urine. Duration of diarrhea was estimated based on stools physical characteristics.

Results: Eighty nine patients received the placebo milk formula and ninety received the LGG containing formula. Both groups were comparable in their baseline characteristics. Total stool output was significantly larger $(p=0.047)$ in the LGG group $(247.8 \mathrm{ml} / \mathrm{kg})$ than in the placebo group $(195.0 \mathrm{ml} / \mathrm{kg})$. No significant differences were found in duration of diarrhea $(58.5$ hours with LGG vs. 50.4 hours with placebo), rate of treatment failure (2I.I\% with LGG vs. $18.0 \%$ with placebo), and proportion of patients with unresolved diarrhea after 120 hours (I2.2\% with LGG vs. $12.5 \%$ with placebo). The rate of stools with reducing substances after 24 hours of treatment increased significantly in both groups (from $41.4 \%$ to $72.2 \%$ with LGG and from $45.9 \%$ to $68.0 \%$ with placebo).

Conclusion: This study did not show a positive effect of LGG on the clinical course of acute watery diarrhea. Positive beneficial effects of LGG, as had been reported elsewhere, could have been masked in our study by worsening diarrhea due to transient lactose malabsorption. Further studies with low-lactose or non-lactose conveyors of LGG are desirable. 


\section{Background}

Diarrheal diseases in the developing world continue to cause significant morbidity and mortality, especially when associated with malnutrition [1]. Dehydration, potassium depletion and acidosis are the main life-threatening complications of the acute losses during watery diarrhea. More than 25 years of extensive use has demonstrated that these complications could be effectively treated or prevented by oral rehydration therapy [2]. However, the oral glucose-electrolyte rehydration solution such as that recommended by WHO and Unicef neither shortens the duration of the illness nor reduces the stool loss and may cause an increase in stool volume at least during the first hours in children with acute diarrhea [3]. Optimization of the standard WHO-ORS solution, by reducing its osmolarity, has been shown to reduce diarrhea duration, total stool output, and the need for unscheduled intravenous therapy [4].

Adjuvant therapy to ORT, based on oral administration of live probiotic bacteria aimed to improve recovery of infants from acute watery diarrhea, has been under active investigation [5]. These studies, done in the developed world, have shown a benefit only for viral mild gastroenteritis. Isolauri et al have shown that oral bacterial therapy with Lactobacillus casei strain GG (LGG) reduces both the severity and duration of acute non dehydrating rotavirus enteritis [6]. Another trial in Karelia republic, LGG was shown to decrease the duration of acute diarrhea in children with viral acute diarrhea but not in those with bacterial diarrhea [7]. In a multicenter study carried out in Europe, LGG was administrated in a hypotonic oral rehydration solution to children with acute diarrhea, showing that it was safe and resulted in shorter duration of diarrhea, less chance of a protracted course, and faster discharge from the hospital [8].

Limited information is available on the potential role of LGG in infants living in the developing world, with more severe acute watery diarrhea [9], where etiologic agents other than rotavirus are involved more frequently and where mixed infections are more prevalent [10]. We conducted this study aimed to assess the effect of a milk formula containing Lactobacillus casei strain GG (LGG) on the duration and severity of diarrhea in children with acute watery diarrhea from our hospital. The study was conducted in the Rehydration Unit of Cayetano Heredia Hospital in Lima, Peru from September 1991 to June 1992. The study protocol and Consent Form were reviewed and approved by the Ethical Committee of Cayetano Heredia University in compliance with the Helsinki Declaration.

\section{Methods \\ Study population}

Male infants 3-36 months of age brought for treatment because of acute diarrhea to the Rehydration Unit of Cayetano Heredia Hospital, Lima during September 1991 to June 1992 were eligible for the study if they met the following criteria: (a) a history of three or more watery stools per day for less than 48 hours, (b) no bloody stools at the moment of first examination, (c) clinical signs of dehydration, (d) no clinical features of hypovolemic shock, (e) no clinical signs of a coexisting acute systemic illness (i.e., meningitis, sepsis, pneumonia) or a recognized chronic disease such as pulmonary tuberculosis, and ( $\mathrm{f}$ ) no history of current antibiotic or antidiarrheal medication use. Patients 3-6 months old were considered for the study only if they were not on exclusive breastfeeding. Patients were not selected if their weight for age was less than $60 \%$ of the median weight for age established by the National Center for Health and Statistics (NCHS) [11]. Only patients whose parent or legal guardian was willing and able to give written informed consent were admitted to the study. Only male patients were selected in order to facilitate separate collection of stools and urine. The study size was calculated expecting a 33\% reduction in duration of diarrhea and mean volume of diarrhea stool for a significance level of 0.05 and a power of $80 \%$.

\section{Study design}

Infants fulfilling the admission criteria were randomly assigned to a double-blind comparison of a milk formula containing $10^{9} \mathrm{cfu} / \mathrm{ml}$ of Lactobacillus casei strain GG (LGG) or a similar milk formula not containing LGG. Both formulas were of identical looking and tasting. Both milk formulas were provided by the manufacturer (Valio Ltd, Helsinki, Finland) as milk powder to reconstitute with water. They were given in bottles, appropriately labeled and number-coded for each child to secure the double-blind design. The actual assignment of children to their study numbers was made at the time of their enrollment into the study. Each child admitted into the study was allocated to either treatment group by restricted randomization using random permuted blocks. The codes were prepared in Finland and kept in sealed envelopes in Lima.

\section{Baseline assessment}

A clinical history and physical examination was completed upon admission to identify the patient, to determine the duration, type and severity of his diarrhea, to assess associated clinical features (fever, vomiting, dehydration, abdominal pain, distension), and to establish the nutritional status and previous dietary regimen of the subject. Blood for determination of serum sodium, potassium, chloride, glucose and bicarbonate, blood urea nitrogen, microhematocrit and plasma specific gravity 
was drawn from each patient before starting treatment. A routine urine analysis was also made. Fecal samples or rectal swabs taken at admission were transported in CaryBlair transport medium to Cayetano Heredia University Microbiology Laboratory for primary isolation and identification of bacterial enteropathogens. A separate vial containing phosphate buffer saline was used to transport fecal specimens for rotavirus examination.

\section{Microbiologic methods}

Specimens were cultured for Salmonella, Shigella, E. coli and Vibrios by standard direct and enrichment enteric media. Campylobacter was selectively cultured on sheep blood agar containing Butzler's antibiotic supplement and Aeromonas on ampicillin blood agar preceded by overnight enrichment in alkaline peptone water. Five lactose fermenting colonies of $E$. coli isolates per patient were serotyped according to standard methods using polyvalent sera for the recognition of enteropathogenic E. coli. Detection of Rotavirus was made by ELISA method using Rotazime $^{\circledast}$. Identification of enterotoxigenic strains of E. coli was not done. Details of the microbiologic methods used in this study are described in detail elsewhere [10].

\section{Rehydration}

The degree of dehydration was assessed clinically. Dehydration was corrected and then fluid balance maintained using the oral rehydration salts (ORS) in its standard WHO's recommended formulation, following the WHO Guidelines [12]. Briefly, each child was given approximately $100 \mathrm{ml} / \mathrm{kg}$ of ORS during the first four hours. The ORS was administered in frequent sips using a spoon or by nasogastric tubes if vomit or stool output rates were high. Children were not given other fluid or foods during this period. Upon completion of this period, on-going fecal losses were replaced with the same solution, on a volume to volume basis until diarrhea ceased.

\section{Administration of the study formula}

Once dehydration was corrected, feeding, including administration of the assigned study formula was initiated. The first dose of the assigned study formula was administered as soon as rehydration was completed and subsequent doses were given every four hours until cessation of diarrhea or for a maximum of five days. The formula was prepared immediately before administration of each dose by a specially trained nurse that was exclusively working for the study. Measuring spoons provided by the manufacturer were used and the formula powder was kept refrigerated all the time once the container was opened. Before use, the sachets with the study formulas were kept in a $-20^{\circ} \mathrm{C}$ refrigerator. The formula powder was diluted in warm boiled water as to provide $670 \mathrm{Kcal}$ per liter. The amount of formula given to each child was calculated based on the child's body weight, each child being given
$150 \mathrm{ml} / \mathrm{kg} /$ day to a maximum of $1000 \mathrm{ml} /$ day. On average, each serving of $100 \mathrm{ml}$ will supply $10^{11} \mathrm{cfu}$ of LGG for those receiving the formula containing LGG. Administration of the formula was by bottle and not compulsive. If the child refused to drink the formula after reasonable attempts, no extraordinary methods, like delivery via nasogastric tubing, were used; in this situation the formula was offered again four hours later.

\section{Other foods given}

Patients under six months of age were fed only the randomly assigned study formula to provide a daily caloric intake of at least $100 \mathrm{Kcal} / \mathrm{kg}$ (in a volume of $150 \mathrm{ml} / \mathrm{kg} /$ day). No other foods were given for these under six months patients. Older patients were fed the assigned formula ad libitum for a maximum of $1000 \mathrm{ml} /$ day. Caloric requirements were completed with a blended soft baby food prepared from fresh ingredients (chicken breast, rice, carrots, squash, potatoes, and vegetable oil), by the Hospital's Nutrition Department. This soft baby food provides $1 \mathrm{Kcal}$ per gram (approximately, 10\% of its calories as protein, $45 \%$ as carbohydrates and $45 \%$ as fats). A total of at least $100 \mathrm{Kcal} / \mathrm{kg} /$ day (including the calories provided by the study formula) were offered to these children.

\section{Measurement of clinical outcomes}

All oral intake (ORS, study formula, breast milk, plain water, soft baby food) as well as urine, stool and vomitus volume were strictly measured and recorded during hospitalization. For this purpose patients were put on metabolic beds (which have a hole in the mattress were a container was placed to allow direct stool collection). A urine collection bag was fitted to avoid contamination of stools with urine and to measure the urine volume. After the first 72 hours, differential weight of dry and soiled diapers was used instead the metabolic bed to determine stool weight if the previous observed purging rate was below $5 \mathrm{ml} / \mathrm{kg} /$ hour. Blood analyses taken at admission were repeated at 24 hours. Stool examination for $\mathrm{pH}$, glucose, reducing substances, leukocytes and microscopic fat were performed at admission, 24, 72 hours and at discharge. Urine specific gravity was determined every 24 hours until discharge.

\section{Criteria for stopping treatment and discharging the patient}

Patients were discharged from the study 24 hours after cessation of diarrhea, or at the end of five days from admission, or at the time treatment failure occurred. At discharge each patient was categorized as have completed the trial, as a treatment failure, as an unresolved diarrhea situation, or as a withdrawal. 


\section{Primary outcomes}

- Rate of treatment failure: proportion of patients in each study group who have recurrence or continued presence of more than 5\% dehydration, worsening electrolyte abnormalities, no weight gain since admission, developing of ileus or severe diarrhea defined as a purging rate in excess of $10 \mathrm{ml} / \mathrm{Kg} / \mathrm{hr}$ in two consecutive 4-hour periods.

- Rate of unresolved diarrhea after five days of treatment: proportion of patients in each study group with continuing diarrhea after five days of treatment.

- Duration of diarrhea: time in hours from admission until cessation of diarrhea

- Duration of hospitalization: time in hours from admission until discharge from hospital. Patients with treatment failure are excluded.

- Total stool output: volume of diarrheic stools collected from admission until cessation of diarrhea or for a maximum of 120 hours if diarrhea continues, expressed in milliliters per kilogram of body weight.

- Total intake of oral rehydration solution: volume of ORS taken from admission until cessation of diarrhea or for a maximum of 120 hours if diarrhea continues, expressed in milliliters per kilogram of body weight.

\section{Secondary outcomes}

- Total study formula intake: volume of study formula taken from admission until cessation of diarrhea or for a maximum of 120 hours if diarrhea continues, expressed in milliliters per kilogram of body weight.

- Total energy intake: energy from all sources (ORS, formula) taken from admission until cessation of diarrhea or for a maximum of 120 hours if diarrhea continues, expressed in kilocalories per kilogram of body weight.

- Total volume of vomitus: volume of vomitus collected each day from admission until cessation of vomitus or for a maximum of 120 hours, expressed in milliliters per kilogram of body weight.

- Total volume of urine: volume of urine collected each day from admission until cessation of diarrhea or for a maximum of 120 hours, expressed in milliliters per kilogram of body weight.

\section{Working definitions}

The following definitions were used for this study:

- Carbohydrate malabsorption: stool sample giving a positive reaction for reducing substances $(0.75 \mathrm{~g} \%$ or above).
- Cessation of diarrhea: passage of formed stool or passage of no stool for 12 consecutive hours.

- Early withdrawal: patient who (a) developed a complicating illness, (b) presented bloody diarrhea after admission and before five days of treatment, (c) was prematurely discharged under request of his parent or legal guardian, or (d) had any protocol violation or noncompliance.

\section{Statistical analysis}

The data, initially collected in pre-coded forms, were entered in a database organized with a relational model under Fox Pro ${ }^{\circledR}$ v. 1.02 (Dbase ${ }^{\circledR}$ compatible formats) using a data entry program with on-line checking. The data was checked again in batch mode and finally transferred to EpiInfo $^{\circledast}$ for Windows ${ }^{\circledR}$ v. 3.01 (November 2003) where the tabulations and statistical analysis were performed. Letters (A or B, maintaining blindly the treatment group assignment) identified treatment groups until all statistical analysis was completed. Only after completing the analysis investigators unblinded the treatment assignment. Baseline and outcome two-way comparisons were made between the two treatment groups. A 5\% level of significance for statistical tests was set in advance for all comparisons. Chi-square Yates corrected was used to compare discrete variables. One way analysis of variance was performed for continuous variables. Data from patients prematurely withdrawn from the study was included in the analysis up to the time of withdrawal (intention-totreat analysis).

\section{Results}

A total of 179 patients were admitted into the study, 90 in the LGG group and 89 in the control group. Nineteen patients, eight from the LGG group and 11 from the control group, were prematurely withdrawn from the study (figure 1) because of either one of the following reasons: bloody stools within the first 24 hours after admission (11 patients); parental non-compliance (four patients); no diarrheal stools passed within the first 24 hours since admission (two patients); typical severe cholera-like diarrheal disease improperly included (one patient); and severe systemic infection present but not recognized at admission (one patient).

\section{Baseline characteristics}

Table 1 presents the baseline characteristics of patients upon admission. The treatment groups were comparable in age, nutritional status, and other clinical and laboratory variables. Marginal differences were found, however, in stool output during the first four hours of the rehydration phase, before administration of the study formula. The LGG group was thus comprised by slightly more severe cases. Table 2 shows stool microbiology and parasitology 
Table I: Clinical and laboratory features on admission

\begin{tabular}{|c|c|c|c|c|c|}
\hline & Placebo group & $\mathbf{N}$ & LGG group & $\mathbf{N}$ & $\mathbf{P}$ \\
\hline Age (months) & $14.7 \pm 6.4$ & 89 & $14.9 \pm 7.5$ & 90 & 0.878 \\
\hline Duration of diarrhea before admission (h) & $29.5 \pm 14.9$ & 89 & $28.8 \pm 14.9$ & 90 & 0.733 \\
\hline $\mathrm{N}^{\circ}$ of stool motions $24 \mathrm{~h}$ before admission & $6.6 \pm 3.2$ & 89 & $7.5 \pm 3.9$ & 90 & 0.101 \\
\hline $\mathrm{N}^{\circ}$ of patients with vomitus $24 \mathrm{~h}$ before admission & 64 (7I.9\%) & 89 & $66(73.3 \%)$ & 90 & 0.963 \\
\hline $\mathrm{N}^{\circ}$ of patients with fever $24 \mathrm{~h}$ before admission & $39(43.8 \%)$ & 89 & $43(47.8 \%)$ & 90 & 0.703 \\
\hline Clinical dehydration & & 89 & & 90 & 0.165 \\
\hline Mild & 48 (53.9\%) & & $36(40.0 \%)$ & & \\
\hline Moderate & 40 (44.9\%) & & $52(57.8 \%)$ & & \\
\hline Severe & $\mathrm{I}(\mathrm{I} .1 \%)$ & & $2(2.2 \%)$ & & \\
\hline$\%$ of weight gain after rehydration & $3.0 \pm 2.2$ & 89 & $3.1 \pm 2.3$ & 90 & 0.763 \\
\hline Fever at admission $\left(\geq 37.5^{\circ} \mathrm{C}\right)$ & $16(18.0 \%)$ & 89 & $14(15.9 \%)$ & 88 & 0.868 \\
\hline Weight for height* & $94.8 \pm 9.3$ & 89 & $94.1 \pm 7.6$ & 90 & 0.551 \\
\hline Height for age* & $88.9 \pm 12.1$ & 89 & $97.2 \pm 3.7$ & 90 & 0.546 \\
\hline Weight for age* & $88.9 \pm 12.1$ & 89 & $88.9 \pm 10.8$ & 90 & 0.952 \\
\hline Stool output (ml/kg) first $4 \mathrm{~h}$ (rehydration phase) & $14.4 \pm 12.4$ & 89 & $18.1 \pm 16.1$ & 90 & 0.085 \\
\hline Hematocrit $(\%)$ & $35.0 \pm 4.2$ & 89 & $35.5 \pm 3.8$ & 90 & 0.426 \\
\hline Plasma specific gravity & $1.028 \pm 0.002$ & 89 & $1.028 \pm 0.002$ & 90 & 0.769 \\
\hline Serum $\mathrm{Na}^{+}(\mathrm{mEq} / \mathrm{l})$ & $136.6 \pm 4.7$ & 89 & $136.4 \pm 4.6$ & 87 & 0.770 \\
\hline Serum $\mathrm{K}^{+}(\mathrm{mEq} / \mathrm{l})$ & $4.0 \pm 0.7$ & 89 & $4.0 \pm 0.7$ & 87 & 0.985 \\
\hline Serum $\mathrm{Cl}(\mathrm{mEq} / \mathrm{l})$ & $102.5 \pm 5.2$ & 89 & $102.6 \pm 5.4$ & 87 & 0.874 \\
\hline Serum total CO2 (mmol/l) & $14.0 \pm 3.9$ & 88 & $14.0 \pm 3.9$ & 87 & 0.971 \\
\hline Blood urea nitrogen (mg/dl) & $13.1 \pm 10.5$ & 70 & $11.4 \pm 6.6$ & 73 & 0.253 \\
\hline Blood glucose $(\mathrm{mg} / \mathrm{dl})$ & $107.5 \pm 33.4$ & 88 & $106.5 \pm 35.9$ & 88 & 0.848 \\
\hline $\mathrm{N}^{\circ}$ of patients with fecal leukocytes (> $20 \mathrm{PMN} / \mathrm{hpf}$ ) & $30(34.5 \%)$ & 87 & $21(23.6 \%)$ & 89 & 0.154 \\
\hline $\mathrm{N}^{\circ}$ of patients with microscopic fat & $56(64.4 \%)$ & 87 & $52(58.4 \%)$ & 89 & 0.513 \\
\hline Fecal $\mathrm{pH}$ & $6.3 \pm 1.1$ & 87 & $6.6 \pm 1.1$ & 89 & 0.126 \\
\hline $\mathrm{N}^{\circ}$ of patients with $\mathrm{CHO}$ malabsorption & $39(45.9 \%)$ & 85 & $36(41.4 \%)$ & 87 & 0.659 \\
\hline
\end{tabular}

$* \%$ of $\mathrm{NCHS}$ median

Values are mean \pm SD or $n(\%)$

Table 2: Stool microbiology and parasitology at admission

\begin{tabular}{|c|c|c|c|c|c|}
\hline & Placebo group & $\mathbf{N}$ & LGG group & $\mathbf{N}$ & $\mathbf{P}$ \\
\hline Rotavirus & 33 (39.3\%) & 84 & $22(24.4 \%)$ & 90 & 0.052 \\
\hline EPEC & $12(17.6 \%)$ & 68 & $9(13.2 \%)$ & 68 & 0.635 \\
\hline Vibrio cholerae & $7(8.0 \%)$ & 88 & $\mathrm{II}(12.4 \%)$ & 89 & 0.471 \\
\hline Campylobacter sp. & $6(6.8 \%)$ & 88 & $9(10.1 \%)$ & 89 & 0.605 \\
\hline Shigella sp. & $9(10.2 \%)$ & 88 & $4(4.5 \%)$ & 89 & 0.241 \\
\hline Aeromonas sp. & $2(2.3 \%)$ & 88 & I (I.I\%) & 89 & 0.992 \\
\hline Salmonella sp. & $0(0.0 \%)$ & 88 & I (I.I\%) & 89 & 0.995 \\
\hline Negative microbiology & $25(36.8 \%)$ & 68 & $32(47.1 \%)$ & 68 & 0.452 \\
\hline Cryptosporidium parvum & $6(7.0 \%)$ & 86 & $2(2.2 \%)$ & 89 & 0.256 \\
\hline Giardia lambliae & $2(2.3 \%)$ & 86 & $3(3.4 \%)$ & 89 & 0.969 \\
\hline Strongyloides stercolaris & I (1.2\%) & 86 & $0(0.0 \%)$ & 89 & 0.986 \\
\hline Trichomonas sp. & $0(0.0 \%)$ & 86 & $2(2.2 \%)$ & 89 & 0.492 \\
\hline Negative parasitology & 77 (89.5\%) & 86 & $82(92.1 \%)$ & 89 & 0.738 \\
\hline Negative microbiology and parasitology & $22(35.5 \%)$ & 62 & $30(44.8 \%)$ & 67 & 0.371 \\
\hline
\end{tabular}

No patients were found positive for the following parasites: Ascaris, Enterobius, Trichuris, E. hystolytica, Ancylostoma, Necator. ETEC identification was not done

Values are $\mathrm{n}(\%)$

at admission. The distribution of enteropathogens was similar between both groups, except for rotavirus which was found more frequently in the placebo group (39.3\%) than in the LGG group (24.4\%) with a marginal statistical significance for the difference $(\mathrm{p}=0.052)$. 


\section{Stool purging reduction}

The mean total stool output (Table 3) was lower in the placebo group $(195.0 \mathrm{ml} / \mathrm{kg})$ than in the LGG group $(247.8 \mathrm{ml} / \mathrm{kg})$ with a marginal statistical significance for the difference $(\mathrm{p}=0.047)$. The difference between means in total stool output was $-52.8 \mathrm{ml} / \mathrm{kg}$, with $95 \%$ confidence limits between -105.4 to $-0.2 \mathrm{ml} / \mathrm{kg}$.

\section{Duration of diarrhea}

The proportion of patients with unresolved diarrhea after 120 hours was similar in both treatment groups (table 3 ). For those patients that ceased diarrhea during the study period the mean duration of diarrhea was similar between groups (table 3). The difference between means in duration of diarrhea was 8.1 hours with $95 \%$ confidence limits between -19.6 hours to 3.4 .

\section{Blood chemistry}

No patient had to be withdrawn from the study because of worsening blood chemistry abnormalities.

\section{Carbohydrate malabsorption}

The proportion of patients with carbohydrate malabsorption 24 hours after admission into the study was high although not different between the treatment groups (table 4). However, the rate of carbohydrate malabsorption after 24 hours of treatment increased significantly in both treatment groups with respect to admission (table 4). The pH of stools at 24 hours after admission is also significantly lower in both groups compared to the $\mathrm{pH}$ at admission, a result consistent with worsening carbohydrate malabsorption (table 4).

No adverse effects due to the study formula were notice in either group during the study.

\section{Discussion}

Children included into this study probably represent the type of patients with diarrheal disease most frequently seen at a health service in Peru before the cholera epidemic of 1991. They were infants under two years of age, with an episode of acute watery diarrhea, presenting with signs of mild to moderate dehydration and a slight compromise of the nutritional status. Thus, we can conclude that the results of this study can be applied to most cases of acute watery non-cholera diarrhea seen in this population setting.

The comparison of baseline characteristics showed no significant differences between groups. Marginal differences (not statistically significant) were observed in two variables that measure severity of illness: stool frequency 24 hours before admission and stool output during rehydration phase. Both were higher in the LGG group. Other indicators of severity, like clinical estimate of dehydra- tion, percentage of weight gain after rehydration and proportion of patients with vomitus before admission, were similar between both groups. On the other hand, there were more cases (not statistically significant) of rotavirus in the placebo group than in the LGG group. In order to make sure that the groups were in fact comparable, we perform the statistical adjustment for these variables using multiple regression analysis and found no association with the principal outcomes (results of this analysis are not shown in the report).

In more than $55 \%$ of patients an enteropathogen could be identified. This figure could be higher because studies for ETEC were not done. The most prevalent agents were rotavirus (30.7\%), EPEC (11.7\%), Vibrio cholerae (10.1\%) and Campylobacter sp. (8.4\%), with an important proportion of patients having mixed infections. These findings differ considerably from those of the Finnish clinical trial in which LGG was also tested for efficacy in reducing acute infantile diarrhea [6]. In the Finnish trial, rotavirus accounted for more than $80 \%$ of diarrheal cases, with no cases of bacterial diarrhea. A setting of greater diversity of etiologic agents and frequently co-pathogen association is perhaps more representative of developing countries [10].

The first topic to be discussed here is the high proportion of patients that did not recovered optimally during the trial, a condition that did not depend on the assigned treatment group. About $12 \%$ of patients had an unresolved diarrhea and an additional $20 \%$ were classified as treatment failures, mostly due to severe diarrhea. In two clinical trials conducted at our unit similar rates were found. For instance, in a clinical trial designed to test the clinical efficacy of a citrate-based ORS in children with acute watery diarrhea, patients who received standard therapy (WHO-ORS) had a treatment failure rate of about $24 \%$ [13]. This rate was $40 \%$ if only rotavirus associated diarrhea was considered. In another study, in which a chicken soup-based ORS was evaluated for children with similar characteristics (not published), 15.4\% treatment failure rate for all subjects standard and 20\% for those with rotavirus was observed. In the Finnish study, all children recovered before 5 days and no treatment failures were reported [6]. This striking difference could be explained in part by dissimilar etiologies as was mentioned above. Bacterial diarrhea and infection with more than one pathogen might produce a more severe illness. The nutritional status is also important to explain the difference. It has been well established from studies in developing countries that diarrhea lasts longer in poorly nourished children [14]. This difference seems to be important even when only slight malnutrition is present, as is the case for the patients admitted into this study. 
Table 3: Clinical outcomes

\begin{tabular}{|c|c|c|c|c|c|c|}
\hline & Placebo group & $\mathbf{N}$ & LGG group & $\mathbf{N}$ & $\mathbf{P}$ & Difference between means \\
\hline Discharge condition & & 89 & & 90 & & \\
\hline Early withdrawal & II (I2.4\%) & & $8(8.9 \%)$ & & 0.609 & \\
\hline Treatment failure & $16(18.0 \%)$ & & $19(21.1 \%)$ & & 0.734 & \\
\hline Cessation of diarrhea & $51(57.3 \%)$ & & $52(57.8 \%)$ & & 0.931 & \\
\hline Unresolved diarrhea & $11(12.45 \%)$ & & $11(12.2 \%)$ & & 0.842 & \\
\hline Mean duration of diarrhea (hours)* & $50.4 \pm 28.0$ & 51 & $58.5 \pm 30.2$ & 52 & 0.157 & -19.6 to 3.4 \\
\hline Mean duration of hospitalization (hours)** & $74.7 \pm 33.7$ & 62 & $81.2 \pm 32.6$ & 63 & 0.280 & -18.4 to 5.4 \\
\hline Total stool output (ml/kg) & $195.0 \pm 171.9$ & 89 & $247.8 \pm 180.2$ & 90 & 0.047 & -105.4 to -0.2 \\
\hline Total oral rehydration solution intake $(\mathrm{ml} / \mathrm{kg})$ & $236.5 \pm 195.6$ & 89 & $272.8 \pm 188.1$ & 90 & 0.208 & -93.7 to 21.1 \\
\hline Total study formula intake $(\mathrm{ml} / \mathrm{kg})$ & $215.5 \pm 136.3$ & 89 & $231.5 \pm 136.6$ & 90 & 0.435 & -56.8 to 24.8 \\
\hline Total energy intake $(\mathrm{Kcal} / \mathrm{kg})^{\S}$ & $220.7 \pm 140.4$ & 89 & $247.4 \pm 143.0$ & 90 & 0.209 & -69.1 to 15.7 \\
\hline Total volume of vomitus (ml/kg) & $27.6 \pm 45.5$ & 89 & $27.4 \pm 33.9$ & 90 & 0.968 & -11.8 to 12.2 \\
\hline Total volume of urine $(\mathrm{ml} / \mathrm{kg})$ & $81.5 \pm 65.2$ & 89 & $87.1 \pm 69.4$ & 90 & 0.579 & -25.7 to 14.5 \\
\hline
\end{tabular}

* For patients who ceased diarrhea before 120 hours.

** Patients with treatment failure or early withdrawals are excluded.

$\S$ Calculated from calories provided by study formula, soft foods, breastmilk, and oral rehydration solution.

Values are mean $\pm S D, n(\%)$, or $95 \%$ confidence limits.

Table 4: Comparison of stool characteristics at admission and 24 hours after

\begin{tabular}{lccccc}
\hline & Admission & N & 24 h later & N & P \\
\hline $\begin{array}{l}\text { Fecal pH } \\
\quad \text { Placebo group }\end{array}$ & $6.3 \pm 1.1$ & 87 & $5.9 \pm 0.8$ & 76 & 0.014 \\
$\quad$ LGG group & $6.6 \pm 1.1$ & 89 & $6.1 \pm 0.9$ & 74 & 0.004 \\
CHO malabsorption & & & $51(68.0 \%)$ & 75 & 0.008 \\
$\quad$ Placebo group & $39(45.9 \%)$ & 85 & $52(72.2 \%)$ & 72 & $<.001$ \\
LGG group & $36(41.4 \%)$ & 87 & & \\
\hline
\end{tabular}

Values are mean $\pm \mathrm{SD}$ or $\mathrm{n}(\%)$

Except for total stool output (which showed a marginal statistical significance), no significant differences in the principal outcomes between groups were found. Duration of diarrhea, duration of hospitalization, and total ORS intake were not significantly different between the experimental and placebo group. The mean volume of formula (and of lactose) administered to children was the same for both groups. The confidence limits of the difference between the two groups indicate that a maximum reduction on duration of diarrhea of $6.7 \%$ attributable to the LGG formula could have been detected with the sample size of this study. These numbers indicate that the study does have a sample size sufficient to reject a type II error. No positive effects of treatment could be demonstrated as opposed to Isolauri's experience in Finland [6]. The dose factor could not explain the difference between the two studies. The dose of LGG in Isolauri's study was $2 \times 10^{10-}$ ${ }^{11}$ cfu per day [6]. The dose of LGG in our study was $6-8 \times$ $10^{11}$ cfu per day, well above the threshold dose of 10 billion cfu suggested as most effective [15]. Viability of the
Lactobacillus GG in the sachets while stored in Lima was not confirmed bacteriologically.

There were slightly fewer cases of rotavirus in the LGG group than in the placebo group $(24.4 \%$ vs. $39.3 \%)$, although the difference was not statistically significant. LGG appears to be more effective in viral than in bacterial diarrhea [8]. These facts could explain in part the lack of beneficial effect of LGG in our study. It is possible that LGG was not able to colonize the gut of our patients in the presence of bacterial pathogens. Although colonization has been documented during rotavirus diarrhea in children [16], to our knowledge this ability has not been demonstrated when other intestinal pathogens are involved. Colonization properties of LGG in patients with bacterial enteritis would deserve further studies.

Our study clearly shows that the rate of carbohydrate malabsorption raised in both treatment groups from $43.6 \%$ at admission to $70.1 \% 24$ hours later. The amount of lactose 


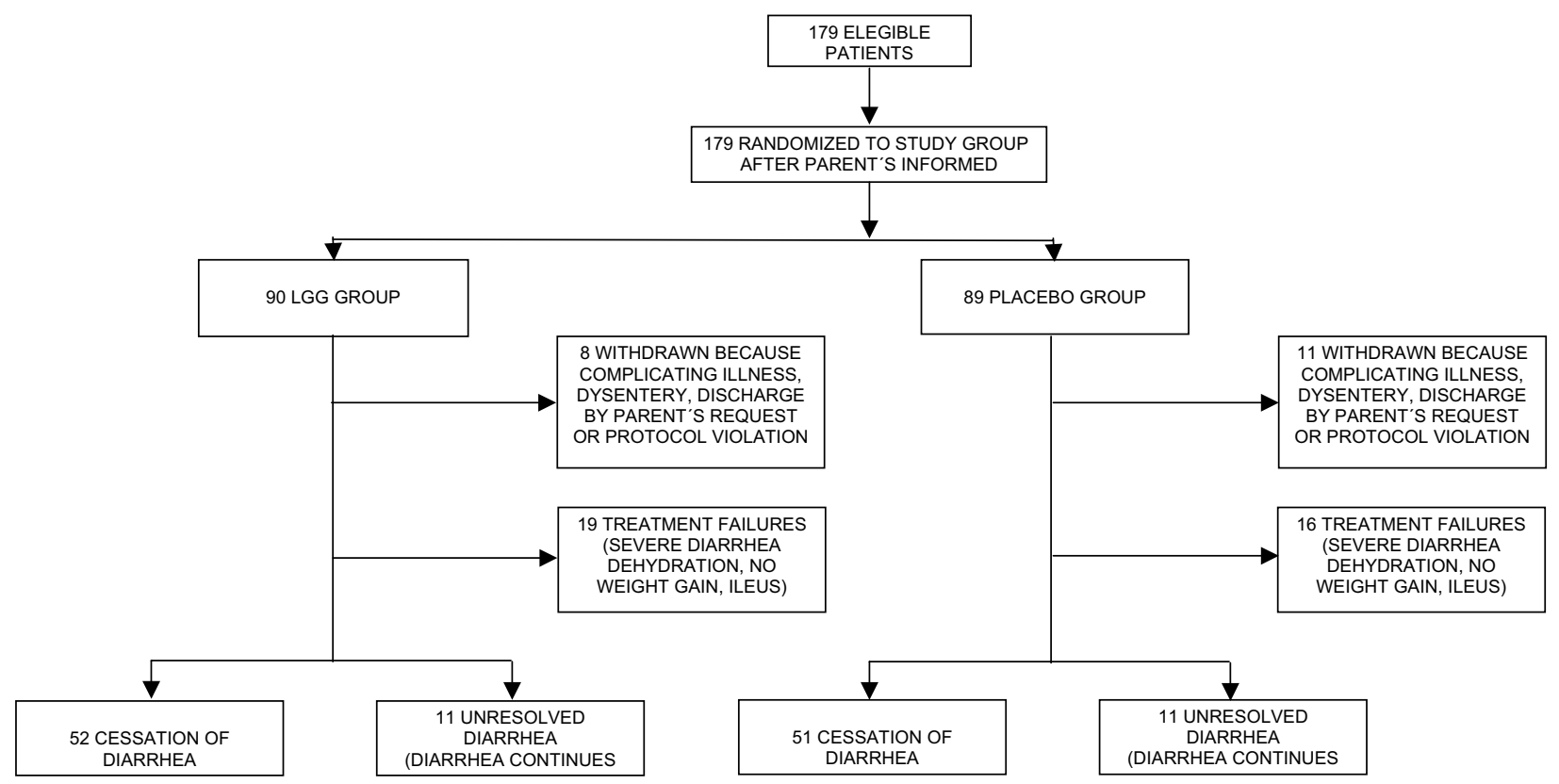

Figure I

Diagram showing the flow of study subjects throughout the study

offered to patients in this study was much higher than in the usual feeding regimen at our unit $(10.5 \mathrm{~g} / \mathrm{kg} /$ day vs. $3.7 \mathrm{~g} / \mathrm{kg} /$ day, respectively). Although to some investigators lactose intolerance is becoming a decreasing problem [17], it is clear from these data that lactose malabsorption as a factor cannot be dismissed. We had consistently found a high proportion of patients with carbohydrate malabsorption in all similar studies conducted in our unit. Thus, one possible explanation for the lack of efficacy of LGG in our patients is that worsening diarrhea due to lactose malabsorption could have masked any beneficial effect of the LGG. If this is true, then reducing the lactose content of the formula might reveal a positive effect. Another option is to deliver the LGG in suitable non-lactose containing infant food that could be given to diarrheic children as part of their treatment. Carefully conducted studies might prove this hypothesis.

\section{Conclusions}

Both groups were comparable in their baseline characteristics. Marginal differences were found in variables that measured severity of illness before treatment. Total stool output was slightly higher in the LGG group reaching a marginal statistical significance. No significant differences in the other principal outcome variables were found between treatment groups. The proportion of patients with unresolved diarrhea after 120 hours was similar in both treatment groups. For those patients that ceased diarrhea during the study period the mean duration of diarrhea was similar between groups. The rate of carbohydrate malabsorption after 24 hours of treatment increased significantly in both treatment groups.

\section{Competing interests}

None declared.

\section{Authors' contributions}

ES-L participated in the design of the study, organized and coordinated the study, participated in the statistical analysis and drafted the manuscript. PM-L carried out the clinical work, participated in the statistical analysis and the drafting of the manuscript. MC-S carried out the statistical analysis. EC-W participated in the clinical work. RBS conceived of the study, and participated in its design and drafting of the manuscript. All authors read and approved the final manuscript

\section{Acknowledgements}

The study was supported by a grant from Valio Ltd, Helsinki, Finland to the Child Health Foundation, Columbia, Maryland. 


\section{References}

I. Bern C, Martines J, de Zoysa I, Glass RI: The magnitude of the global problem of diarrhoeal disease: a ten-year update. Bull World Health Organ 1992, 70:705-7I4.

2. Santosham M, Keenan EM, Tulloch J, Broun D, Glass R: Oral rehydration therapy for diarrhea: an example of reverse transfer of technology. Pediatrics 1997, I00:EI0.

3. el-Mougi M, el-Akkad N, Hendawi A, Hassan M, Amer A, Fontaine $O$, Pierce NF: Is a low-osmolarity ORS solution more efficacious than standard WHO ORS solution? J Pediatr Gastroenterol Nutr 1994, I 9(I):83-6.

4. Choice Study Group: Multicenter, randomized, double-blind clinical trial to evaluate the efficacy and safety of a reduced osmolarity oral rehydration salts solution in children with acute watery diarrhea. Pediatrics 2001, 107:613-618.

5. Rautanen T, Isolauri E, Salo E, Vesikari T: Management of acute diarrhoea with low osmolarity oral rehydration solutions and Lactobacillus strain GG. Arch Dis Child 1998, 79:157-160.

6. Isolauri E, Juntunen $M$, Rautanen T, Sillanaukee $P$, Koivula $T$ : A human Lactobacillus strain (Lactobacillus casei sp strain GG) promotes recovery from acute diarrhea in children. Pediatrics |99|, 88:90-97.

7. Shornikova AV, Isolauri E, Burkanova L, Lukovnikova S, Vesikari T: A trial in the Karelian Republic of oral rehydration and Lactobacillus GG for treatment of acute diarrhoea. Acta Paediatr 1997, 86:460-465.

8. Guandalini S, Pensabene L, Zikri MA, Dias JA, Casali LG, Hoekstra H, Kolacek S, Massar K, Micetic-Turk D, Papadopoulou A, de Sousa JS, Sandhu B, Szajewska H, Weizman Z: Lactobacillus GG administered in oral rehydration solution to children with acute diarrhea: A multicenter European trial. J Pediatr Gastroenterol Nutr 2000, 30:54-60.

9. Costa-Ribeiro H, Ribeiro TC, Mattos AP, Valois SS, Neri DA, Almeida P, Cerqueira CM, Ramos E, Young RJ, Vanderhoof JA: Limitations of probiotic therapy in acute, severe dehydrating diarrhea. J Pediatr Gastroenterol Nutr 2003, 36(I): I I 2-5.

10. Pazzaglia G, Sack RB, Salazar-Lindo E, Yi A, Chea E, Leon-Barua R, Guerrero CE, Palomino J: High frequency of coinfecting enteropathogens in Aeromonas - associated diarrhea of hospitalized Peruvian infants. J Clin Microbiol I99।, 29: I I I I- I I56.

II. Kuczmarski R, Orden S, Grummer-Strawn L, Flegal K, Guo S, Wei R, Mei Z, Curtin L, Roche A, Johnson C: CDC Growth Charts: United States. Advance Data From Vital and Health Statistics of The Center For Disease Control and Prevention 2000. Number 314

12. A manual for the treatment of acute diarrhoea for use by physicians and other senior health workers. Geneva: World Health Organization 1990. WHO/CDD/SER/80.2

13. Salazar-Lindo E, Sack RB, Chea-Woo E, Leon-Barua R, Kay BA, Yi A Robertson $\mathrm{AD}$ : Bicarbonate versus citrate in oral rehydration therapy in infants with watery diarrhea: a controlled clinical trial. J Pediatr 1986, 108:55-60.

14. Black RE, Brown $\mathrm{KH}$, Becker S: Malnutrition is a determining factor in diarrheal duration, but not incidence, among young children in a longitudinal study in rural Bangladesh. Am J Clin Nutr 1984, 39:87-94.

15. Van Niel CW, Feudtner C, Garrison MM, Christakis DA: Lactobacillus therapy for acute infectious diarrhea in children: a meta-analysis. Pediatrics 2002, 109:678-684.

16. Juntunen M, Kirjavainen PV, Ouwehand AC, Salminen SJ, Isolauri E: Adherence of probiotic bacteria to human intestinal mucus in healthy infants and during rotavirus infection. Clin Diagn Lab Immunol 200I, 8:293-296.

17. Editorial: What has happened to carbohydrate intolerance following gastroenteritis? Lancet 1987, I:23-24.

\section{Pre-publication history}

The pre-publication history for this paper can be accessed here:

http://www.biomedcentral.com/1471-2431/4/18/prepub
Publish with Bio Med Central and every scientist can read your work free of charge

"BioMed Central will be the most significant development for disseminating the results of biomedical research in our lifetime. "

Sir Paul Nurse, Cancer Research UK

Your research papers will be:

- available free of charge to the entire biomedical community

- peer reviewed and published immediately upon acceptance

- cited in PubMed and archived on PubMed Central

- yours - you keep the copyright
BioMedcentral 